\title{
AOR
}

Selected Papers of \#AolR2021:

The 22nd Annual Conference of the

Association of Internet Researchers

Virtual Event / 13-16 Oct 2021

\section{SOCIAL MEDIA IN THE AUDIENCE ECONOMY: BUSINESS-TO- BUSINESS PARTNERSHIPS AND CO-DEPENDENCE}

\author{
Fernando N. van der Vlist \\ Utrecht University and University of Siegen \\ Anne Helmond \\ University of Amsterdam
}

\section{Introduction}

Social media platforms are among the world's most profitable businesses and their digital advertising revenues depend considerably on partnerships. Business alliances have become endemic to the advertising market because of its inherent fragmentation: each industry player has a particular role in the digital supply chain while only a handful of players have multiple roles, establishing networks of co-dependence. This is especially the case for the growing ecosystem of programmatic advertising, where ads and audience commodities are automatically traded and served across media distribution channels and geographic regions in mere milliseconds through real-time bidding auctions of 'dizzying computational and organizational complexity' (Alaimo and Kallinikos, 2018: 110). The current global digital advertising market comprises thousands of interconnected platforms and is projected to be $\$ 333$ billion, in which programmatic advertising accounts for the vast majority (84.5\% or more) of total revenue. Social media platforms are uniquely positioned within this complex ecosystem because they play a significant role on both the demand and supply sides of the advertising market. Despite its significance, we do not know enough about the structure of the digital advertising market, how it relates to social media, and the dependence on partnerships and partner integrations.

Business-facing application programming interfaces (APIs) are at the heart of the (programmatic) advertising ecosystem. They facilitate the software development and integration work that is necessary to make programmatic advertising 'work' at a large scale. Access to these business software tools is typically governed through partner programmes. Social media platforms form strategic business partnerships through

Suggested Citation (APA): van der Vlist, F.N. \& Helmond, A. (2021, October). Social Media in the Audience Economy: Business-to-business Partnerships and Co-dependence. Paper presented at AolR 2021: The 22nd Annual Conference of the Association of Internet Researchers. Virtual Event: AolR.

Retrieved from http://spir.aoir.org. 
partner programmes, which attract advertisers, business partners, media publishers, and content creators. Industry players depend on these partnerships with social media to gain privileged programmatic (API) access to social media advertising tools, products, and services - and their massive data audiences - via these business-facing software tools.

\section{Approach}

This paper considers the significance of business partnerships in the establishment of co-dependence relationships in the social media ecosystem to understand how partners mediate and shape platform power. Partners contribute to the ongoing process of 'platformisation' - the technological extension and economic growth of digital platforms, transforming markets, industries, and societal domains (Helmond, 2015; Helmond et al., 2019; Poell et al., 2019; van der Vlist and Helmond, 2021) - through their collective development of business-to-business platform infrastructures that extend the social media ecosystem. Partners are powerful industry players with 'their own interests, business models, and bottom lines' while remaining relatively invisible to consumers (Braun, 2013: 127) but remain underexplored in the literature on platformisation and platform power. The complexity of this ecosystem, with its specialised terminology and constantly changing structure, poses challenges to regulators and lawmakers, which mostly focus on consumer markets (van Dijck et al., 2019). Nonetheless, this paper identifies key public business partnerships and partner integrations that comprise this global ecosystem.

We trace and visualise the partner relationship networks of the 20 most-used social media. We analyse which relationships exist, which are exclusive or shared, and identify key 'nodes' of power in this ecosystem (Broughton Micova and Jacques, 2020). Industry players, through partnerships and the software integrations they build, integrate social media platforms with what we call the audience economy - a complex global and interconnected marketplace of business intermediaries involved in the creation, commodification, analysis, and circulation of data audiences for digital advertising and marketing.

The empirical analysis is based on platforms' public partner directories. We extracted the names and details for each partner using custom-built scrapers to derive a structured dataset with all these partners' names, descriptions, logos, URLs, specialities, industries, countries, languages, service types, goals, and pricing models. Next, we focus on the partners categorised as data intermediaries. We found and scraped another 50 partner directories, listing 9,941 additional partnerships and integrations, and extracted all names and details. By combining both datasets, we gain a sense of the entire audience economy as it relates to social media through organisational partnerships and through technological (API-based) partner integrations.

\section{Findings}

We suggest several ways in which partners and the platform infrastructure they build mediate and shape platformisation and the implications for platform power. First, partners develop data-sourcing and media distribution infrastructures. Second, any 
partner creates value not just for one platform but for the entire ecosystem and all its members by connecting and integrating the different ends of the audience economy. Third, platform infrastructures for data-sourcing and media distribution developed by partners are typically programmable and programmatic. The affordances of programmatic and programmable infrastructure are controlled through distinct governance strategies for app development and for business and marketing development (additionally governed through partnerships).

We find that partnerships are significant in mediating the impacts of social media in different markets and industries worldwide, particularly through key players in advertising and marketing-related areas. As such, we note that platform power is about more than market or monopoly power alone. Partnerships are endemic and essential to the advertising business of digital platforms. Partners expand the collection, use, and integration of audience data in other industry platforms, services, domains, and industries. As a result, platform power is not just held by a single platform but is in part mediated by partners and dispersed into the platform ecosystem, where governance and control are exercised through infrastructure and partnership agreements.

Business and data partnerships establish and govern the preferred pathways (e.g. digital supply chains) and 'nodes' of connectivity in this ecosystem, which yields strategic and infrastructural power to a handful of social media and industry platforms. In this, business-facing APIs have an important gateway function and serve as a source of infrastructural control for platform owners. These partners represent diverse types of audience intermediaries with distinct business models predicated on privileged access to social media's audience data and marketing and advertising services. Additionally, the prevalence of partnerships between audience intermediaries means that it is exceptionally difficult, if not impossible, to trace the origins and flow of audience data throughout the ecosystem.

The mediation of platform power takes many different forms: from cooperation with digital platforms (e.g. partnerships, integrations, revenue-sharing deals, etc.) to forms of resistance (e.g. industry partnership alliances, open standards, advertising boycotts, etc.). Partnerships simultaneously make data widely accessible and exclusive, while also making it more difficult for new competitors to participate because of the consolidation of strategic and infrastructural power. Furthermore, firms acquire and leverage these forms of power through mergers and acquisitions, whereby they inherit existing partnerships and partner integrations.

\section{References}

Alaimo $\mathrm{C}$ and Kallinikos $\mathrm{J}$ (2018) Objects, metrics and practices: An inquiry into the programmatic advertising ecosystem. In: Living with Monsters? (eds U Schultze, et al.), 2018, pp. 110-123. Springer. DOI: 10.1007/978-3-030-04091-8 9.

Braun J (2013) Transparent Intermediaries: Building the Infrastructures of Connected Viewing. In: Holt J and Sanson K (eds) Connected Viewing. Routledge, pp. 124-143. 
Broughton Micova S and Jacques S (2020) Platform power in the video advertising ecosystem. Internet Policy Review 9(4). Available at:

https://policyreview.info/articles/analysis/platform-power-video-advertising-ecosystem.

Helmond A (2015) The Platformization of the Web: Making Web Data Platform Ready. Social Media + Society 1(2): 1-11. DOI: 10.1177/2056305115603080.

Helmond A, Nieborg DB and van der Vlist FN (2019) Facebook's evolution:

development of a platform-as-infrastructure. Internet Histories 3(2): 123-146. DOI: 10.1080/24701475.2019.1593667.

Poell T, Nieborg D and Dijck J van (2019) Platformisation. Internet Policy Review 8(4). Available at: https://policyreview.info/concepts/platformisation.

van der Vlist FN and Helmond A (2021) How partners mediate platform power: Mapping business and data partnerships in the social media ecosystem. Big Data \& Society 8(1). DOI: $\underline{10.1177 / 20539517211025061 .}$.

van Dijck J, Nieborg D and Poell T (2019) Reframing platform power. Internet Policy Review 8(2). Available at: https://policyreview.info/articles/analysis/reframing-platformpower. 